\title{
A randomized controlled trial of Kundalini yoga in mild cognitive impairment
}

\author{
Harris A. Eyre, ${ }^{1,2,3,4}$ Prabha Siddarth, ${ }^{1}$ Bianca Acevedo, ${ }^{1}$ Kathleen Van Dyk, \\ Pattharee Paholpak, ${ }^{1,5}$ Linda Ercoli, ${ }^{1}$ Natalie St. Cyr, ${ }^{1}$ Hongyu Yang, ${ }^{1}$ \\ Dharma S. Khalsa ${ }^{6}$ and Helen Lavretsky ${ }^{1}$ \\ ${ }^{1}$ Semel Institute for Neuroscience and Human Behavior, UCLA, Los Angeles, California, USA \\ ${ }^{2}$ Discipline of Psychiatry, University of Adelaide, Adelaide, South Australia, Australia \\ ${ }^{3}$ IMPACT SRC, School of Medicine, Deakin University, Geelong, Victoria, Australia \\ ${ }^{4}$ Department of Psychiatry, University of Melbourne, Melbourne, Victoria, Australia \\ ${ }^{5}$ Department of Psychiatry, Faculty of Medicine, Khon Kaen University, Khon Kaen, Thailand \\ ${ }^{6}$ Alzheimer's Research and Prevention Foundation, Tucson, Arizona, USA
}

\section{ABSTRACT}

Background: Global population aging will result in increasing rates of cognitive decline and dementia. Thus, effective, low-cost, and low side-effect interventions for the treatment and prevention of cognitive decline are urgently needed. Our study is the first to investigate the effects of Kundalini yoga (KY) training on mild cognitive impairment (MCI).

Methods: Older participants ( $\geq 55$ years of age) with MCI were randomized to either a 12-week KY intervention or memory enhancement training (MET; gold-standard, active control). Cognitive (i.e. memory and executive functioning) and mood (i.e. depression, apathy, and resilience) assessments were administered at baseline, 12 weeks and 24 weeks.

Results: At baseline, 81 participants had no significant baseline group differences in clinical or demographic characteristics. At 12 weeks and 24 weeks, both KY and MET groups showed significant improvement in memory; however, only KY showed significant improvement in executive functioning. Only the KY group showed significant improvement in depressive symptoms and resilience at week 12 .

Conclusion: KY group showed short- and long-term improvements in executive functioning as compared to MET, and broader effects on depressed mood and resilience. This observation should be confirmed in future clinical trials of yoga intervention for treatment and prevention of cognitive decline (NCT01983930).

Key words: Kundalini yoga, Kirtan Kriya, memory enhancement training, cognition, mild cognitive impairment, mood, resilience

\section{Introduction}

Global population is aging rapidly with the estimated rise to over 2 billion people age $\geq 60$ years by 2050 (UN, 2013) - this will logically lead to increasing rates of cognitive decline. Current data suggest that mild cognitive impairment (MCI) ranges between $10 \%$ and $20 \%$ in samples of older adults (Petersen, 2004). MCI may lead to more serious cognitive issues, including Alzheimer's

Correspondence should be addressed to: Harris Eyre, MBBS, PhD Student, Discipline of Psychiatry, The University of Adelaide, 55 Frome Road, Adelaide, South Australia, 5005, Australia. Phone: +61-407-694-527. Email: harris.eyre@gmail.com. Received 27 Jun 2016; revision requested 7 Sep 2016; revised version received 4 Oct 2016; accepted 6 Nov 2016. First published online 16 January 2017. disease and related dementias' (Petersen, 2004). Thus, innovative and cost-effective treatments are urgently needed for treatment and prevention of cognitive decline, and these types of interventions would be useful if they have practical benefits, including minimal invasiveness, low dependency, and low-risk of interactions with prescription medications.

Mind-body practices including yoga and meditation are increasingly shown to be effective for the treatment of age-related cognitive issues (Lavretsky, 2009). For example, a recent study by Gothe et al. (2014) compared the effects of a yoga intervention versus a stretching-strengthening program over eight weeks in 118 community-dwelling older 
adults, and found significantly improved cognition (i.e. executive function, working memory and efficiency of mental-set shifting, and flexibility) for the yoga group participants compared with the control group. Several reviews of yoga and meditation studies in both healthy and clinical samples, expert meditators and novices, using neural and other physiological measures, suggest that engagement in mind-body practices (including Mindfulness Based Stress Reduction, Vipassana, Kundalini yoga (KY), and Tai Chi) result in improved cognitive function, as well as mood and stress (Lavretsky, 2009; Shahidi et al., 2011; Abbott and Lavretsky, 2013). However, many of these studies did not apply rigorous randomized controlled trial (RCT) design.

One type of meditation from a standard KY practice, Kirtan Kriya (KK), has been studied previously in older adults and caregivers (Black et al., 2013; Lavretsky et al., 2013; Khalsa, 2015; Innes et al., 2016a; 2016b). This yoga practice has existed for hundreds of years. KK was used as a homework exercise and includes chanting the mantra sounds, Saa Taa Naa Maa along with repetitive finger movements, or mudras, and visualizations (mudras). $\mathrm{KK}$ is designed to be balancing and uplifting. The sounds come from the mantra "Sat Nam," which means "my true essence." This secular practice can be adapted to several lengths (e.g. for 11 or 32 minutes). It has been shown to be effective in increasing cognitive and emotional functioning (e.g. less depression, anxiety and stress, and improved mood, sleep, cognition, attention, memory, and resiliency) in dementia caregivers and individuals with cognitive impairment (Black et al., 2013; Lavretsky et al., 2013). Our recent pilot study demonstrated similar response to $\mathrm{KY}$ and memory enhancement training (MET) with respect to improved mood and cognition, with some differences in changes in brain connectivity associated with performance on verbal memory tests (Eyre et al., 2016).

The inclusion of a gold standard intervention for cognitive training is important to compare with mind-body interventions. MET is considered a "gold-standard" technique for enhancing cognitive functioning. The goal of MET is to optimize cognitive functioning to support individuals with life functioning and quality of life (Flak et al., 2014). There is evidence suggesting that MET promotes significant improvements in cognitive performance, memory, and quality of life in studies with healthy, older, and individuals with cognitive issues (Jean et al., 2010; Simon et al., 2012). Thus, MET provides a rigorous control for $\mathrm{KY}$ meditation and may shed light on the specific benefits afforded by each practice, especially related to memory and cognitive functioning. To our knowledge, yoga has never been compared to MET in a direct head-to-head comparative clinical trial.

This study is the first RCT to investigate the effects of KY training on MCI. Participants were randomized to either a 12-week $\mathrm{KY}$ intervention or MET (gold-standard, active control). Cognitive (i.e. memory and executive functioning) and mood (i.e. depression, apathy, and resilience) assessments were administered at baseline, 12 weeks and 24 weeks post-intervention. We hypothesized that (1) both KY and MET would result in improved memory, but $\mathrm{KY}$ would result in broader improvements in both memory and executive function, mood, and resilience compared to MET at 12 weeks; and (2) KY intervention will result in sustained improvement in cognition, mood, and resilience compared to MET at 24 weeks.

\section{Methods}

\section{Study procedures}

All participants were recruited via advertisements from UCLA outpatient clinics and the UCLA Longevity Center Program, and from the community to participate in the "Memory Training Versus Yogic Meditation Training in Older Adults with Subjective Memory Complaints and MCI" study at UCLA from 2013 to 2015 (NCT01983930). This study was approved by the UCLA Institutional Review Board. All participants underwent IRB-approved informed consent procedures prior to enrolling in the study.

\section{Inclusion and exclusion criteria}

Inclusion criteria were as follows: (1) age $\geq$ 55 years; (2) subjective memory complaints; (3) Clinical Dementia Rating (CDR) scale score of 0.5 (Hughes et al., 1982); (4) sufficient English proficiency at the 8th grade level or higher as determined by the word reading subtest of the Wide Range Achievement Test-4 (Wilkinson, 2006) to participate in MET; (5) capacity to provide informed consent.

Exclusion criteria included the following: (1) current or past Axis I psychiatric disorders, or recent unstable medical or neurological disorders; (2) any disabilities preventing participation in the MET or KY conditions (e.g. severe visual or hearing impairment); (3) insufficient English proficiency; (4) a diagnosis of dementia per the DSM-5; (5) Mini Mental Health Examination (Folstein et al., 1975) score of 24 or below; (6) use of psychoactive medications; (7) participation in a psychotherapy that involves cognitive training; 
and (8) participants with prior or current training in yoga.

\section{Screening procedures}

At baseline, participants underwent a screen including the following: (1) an interview by a trained study staff to identify physical and cognitive symptoms; (2) a standard battery of hematologic studies; (3) neurological examination (i.e. the Unified Parkinsons Disease Rating Scale (Fahn, 1987); (4) select memory tests (i.e. the Fluid Object Memory Evaluation (Fuld et al., 1990); and (5) a neuropsychiatric evaluation (Structured Clinical Interview for DSM Disorders) (First et al., February 1996); (6) medical comorbidity was assessed with the Cerebrovascular Risk Factor Prediction Chart (Truelsen et al., 1994); the Cumulative Illness Rating Scale-Geriatric (Fahn, 1987; American Heart Association, 1990; Miller et al., 1992; Endicott et al., 1993; Ware et al., 1994); (7) mood assessments included the Geriatric Depression Scale (GDS) (Yesavage et al., 1982).

\section{Outcome measures}

Participants were assessed at screening and baseline (pre-treatment) and at 12 weeks (post-treatment), and re-assessed at 24-week follow-up. The abovementioned mood measures and adverse events were assessed every 2 weeks for the first 12 weeks of the study, and then monthly until 24-week follow-up. At baseline (pre-intervention), participants were administered an extensive test battery assessing demographic, cognitive, and clinical variables. The same battery of tests was repeated at 12 and 24 week post-intervention.

Primary outcome measures were cognitive and included memory and executive functioning. Verbal memory was measured with the following: (1) the Hopkins Verbal Learning Test (HVLT) (total and delayed recall scores) (Shapiro et al., 1999), (2) the Wechsler Memory Scale (WMS-IV). Visualspatial skills and visual memory were assessed using the Rey Osterrieth (Rey-O) test 3- (immediate) and 30-minute (delayed) recall (Shin et al., 2006). Individual executive functions were assessed using (1) the Trail Making Test part B (Reitan, 1958) to measure cognitive flexibility, (2) the Stroop Word-Color Test (Golden, 1975) to assess response inhibition and the Animal Naming Test (Sager et al., 2006) as a measure of semantic fluency.

Secondary outcomes measures included mood assessments with the GDS (Yesavage et al., 1982), a self-assessment scale often used in geriatric depression trials. We also measured commonly present symptoms of apathy or amotivation by using the Apathy Evaluation Scale (AES) (Marin et al., 1991). Psychological resilience to stress as a target for the mind-body interventions was measured by using the Connor-Davidson Resilience scale (Connor and Davidson, 2003).

Side effects were monitored at each visit using the UKU Side Effect Rating Scale (Lingjaerde et al., 1987). Anticipation of the outcomes was assessed at baseline on the Likert scale of 1-10 (range 1 (dissatisfied) to 10 (completely satisfied), and satisfaction with the outcomes was also assessed on the scale of 1-10 (range 1 (dissatisfied) to 10 (completely satisfied), at weeks 6 and 12. In addition, number of classes attended was monitored for each participant.

\section{Randomization and blinding procedures}

After all baseline test results were reviewed and eligibility criteria were confirmed, participants were randomized to either MET or KY groups using a computer-generated random assignment scheme, which assigns participants in a $1: 1$ ratio to each group in the blocks of $8-10$ subjects. All groups were called "wellness and mental stimulation" groups. All behavioral raters, the principal investigator, all statisticians and data managers were blind to the group assignment, and participants were asked not to disclose their group assignment to the raters. No unblinding occurred in the process of assessment.

\section{Yoga training program}

The KY group engaged in a 60 -minute $\mathrm{KY}$ class per week, and a daily 12-minute $\mathrm{KK}$ meditation and homework assignment. Each 60-minute KY was conducted by the same instructor and followed the following structure: (1) tuning in (5 minutes); (2) warm up (12 minutes); (3) breath techniques "Pranayama" (12 minutes); (4) KK (12 minutes); (5) meditation (15 minutes); (6) rest "Shavasana" and closing ( $\mathrm{min})$. Standardized handouts and CDs were given to participants for their 12-minute home practice of $\mathrm{KK}$ meditation, which includes repetitive finger movements (or mudras), as well as chanting of the mantra "Saa, Taa, Naa, Maa," meaning "Birth, Life, Death, and Rebirth," first chanted aloud, then in a whisper, and silently for the total of 11 minutes followed by a final 1 minute of deep breathing relaxation accompanied by the visualization of light.

\section{Memory enhancement training program}

MET was developed by researchers within the UCLA Longevity Center. It involves a scripted curriculum for trainers and a companion workbook for participants. The standard detailed protocol for the MET program is based on evidence-based 
techniques that use verbal and visual association strategies and practical strategies for memory (Verhaeghen et al., 1992; Gross and Rebok, 2011). MET is manualized and includes several components, including the following: (1) education about memory; (2) pre-training for memory strategies (i.e. "pre-training"); (3) instruction in specific memory strategies; (4) home practice with logs to track activity; (5) addressing noncognitive factors, such as self-confidence, anxiety, and negative expectations; and (6) small (i.e. about 10 persons) group sessions. Each weekly session is organized in the same way; trainers (1) document the number of participants attending the session, collect homework completion logs and assess engagement in alternative treatments; (2) review the previous session's homework to reinforce techniques; (3) teach new techniques, reviews, and conduct in-class exercises; and (4) assign homework. Participants were expected to spend about 20 minutes on homework per day and document in their daily diaries. Each session is devoted to learning and practicing techniques, and 15 minutes are reserved for reviewing homework. Specific techniques taught include the following: visual associative strategies for learning faces and names (adapted from McCarty (1980)); verbal associative techniques (such as the use of stories) to remember lists; organizational strategies (categorizing items on a grocery list); learning memory habits to recall where one places items, what one has done in the recent past (e.g. locking doors, turning off appliances); and how to remember future tasks (i.e. appointments).

\section{Statistical analyses}

All data were entered into the database at the time of their collection and analyzed after completion of the trial. Patients in the treatment groups were compared using t-tests (for continuous variables) or $\chi^{2}$ tests (for categorical variables) on all demographic and clinical measures at baseline to assess the success of the randomization procedures. Completers and dropouts in the two groups were compared using t-tests or $\chi^{2}$ tests. All the outcome measures of interest are continuous and were analyzed using a mixed effects general linear model, as implemented in SAS PROC MIXED. The model included treatment group as the between-subject factor, time as the within-subject factor, and the interaction term between time and treatment group as a predictor. Age, sex, and education were used as covariates. Post hoc analyses determined the significance of specific pair-wise group differences and within-group changes. Effect sizes (ES; Cohen's d) for all outcome measures over time were estimated. The level of significance for outcomes was set at the $\alpha$ level of $\mathrm{p}<0.05$, two-tailed. We did not employ any correction procedures for multiple comparisons, since (1) all the analyses were hypothesis driven and (2) this is the first study comparing KY and MET to examine these measures - we are reporting the results of all analyses and conclusions are based on the pattern of results. This approach thus permits the discovery of important features of the study findings without the reduction of power that would result from correction.

\section{Results}

The CONSORT diagram for the study is shown in Figure 1. After screening 168 participants and in-person diagnostic testing, 85 individuals met criteria for in-person screening and 81 were enrolled into the study, with 79 individuals receiving the allocated intervention.

Table 1 shows the demographic characteristics of the two groups. There were 38 participants (25 women) in the KY group and 41 in the MET group (27 women). The groups did not differ by age, ethnicity, years of education, or BMI. The groups differed significantly in the performance on the Trails B time $(t=-1.98, d f=69, p=0.05)$ and the Stroop Word-Color $(\mathrm{t}=1.98, \mathrm{df}=69, \mathrm{p}=$ $0.05)$ tests. Baseline scores were used as covariates in all analyses.

At the end of the 12-week intervention, nine participants had dropped out from each of the two groups. Drop-out rate did not differ by group allocation. One participant in the yoga group discontinued due to dizziness. No other side effects occurred. We determined that completers and drop-outs in the two groups did not differ significantly in any of the baseline characteristics, except for educational level in the MET group. Completers in the MET group were significantly more educated (17.3 (3.5)) compared to dropouts (15.0 (1.5); $\mathrm{p}=0.02)$. The groups did not differ on the number of classes attended (KY: 7.13 (4.35) vs. MET: 7.14 (4.18); $\mathrm{p}=1.0$ ). Further, satisfaction scores (Week 6 scores: KY: 8.3 (1.3) vs. MET 7.9 (2.3); $\mathrm{p}=0.4$; Week 12 scores: KY: 8.4 (1.8) vs. MET 7.8 (1.8); p =0.3), and anticipation scores (Week 6 scores: KY: 7.9 (1.4) vs. MET 7.7 (2.4); $\mathrm{p}=0.7$; Week 12 scores: KY: 8.5 (1.9) vs. MET 7.8 (1.9); $\mathrm{p}=0.2$ ) also did not differ between the groups.

\section{Analysis of change in memory over time}

There were no between-group differences in memory changes with time; however, there were 
Table 1. Demographic characteristics at baseline for KY and MET groups

\begin{tabular}{|c|c|c|c|c|}
\hline VARIABLE & $\begin{array}{l}\text { KY GROUP } \\
(\mathrm{N}=38)\end{array}$ & $\begin{array}{l}\text { MET GROUP } \\
(\mathrm{N}=41)\end{array}$ & $\begin{array}{l}\text { STATIS T ICS } \\
\mathrm{t}(77) / \chi^{2}(1)\end{array}$ & p-VALUE \\
\hline \multicolumn{5}{|l|}{ Sex } \\
\hline Female & $25(65.8 \%)$ & $27(65.9 \%)$ & 0.00 & 1 \\
\hline Male & $13(34.2 \%)$ & $14(34.1 \%)$ & & \\
\hline \multicolumn{5}{|l|}{ Race } \\
\hline Caucasian & $24(63.2 \%)$ & $30(73.2 \%)$ & 0.90 & 03 \\
\hline Non-Caucasian & $14(36.8 \%)$ & $11(26.8 \%)$ & & \\
\hline Age (years) & $68.1(8.7)$ & $67.6(8.0)$ & 0.29 & 08 \\
\hline Education (years) & $17.4(3.4)$ & $16.7(3.3)$ & 0.92 & 04 \\
\hline $\mathrm{BMI}$ & $26.7(4.9)$ & $25.1(4.7)$ & 1.40 & 02 \\
\hline
\end{tabular}

Figures indicate mean with standard deviation (SD) for the continuous and $\mathrm{N}(\%)$ for the categorical variables; $\mathrm{t}(77)$ are presented for the continuous and $\chi^{2}(1)$ for categorical measures.

$\mathrm{MET}=$ memory enhancement training; $\mathrm{KY}=$ Kundalini yoga.

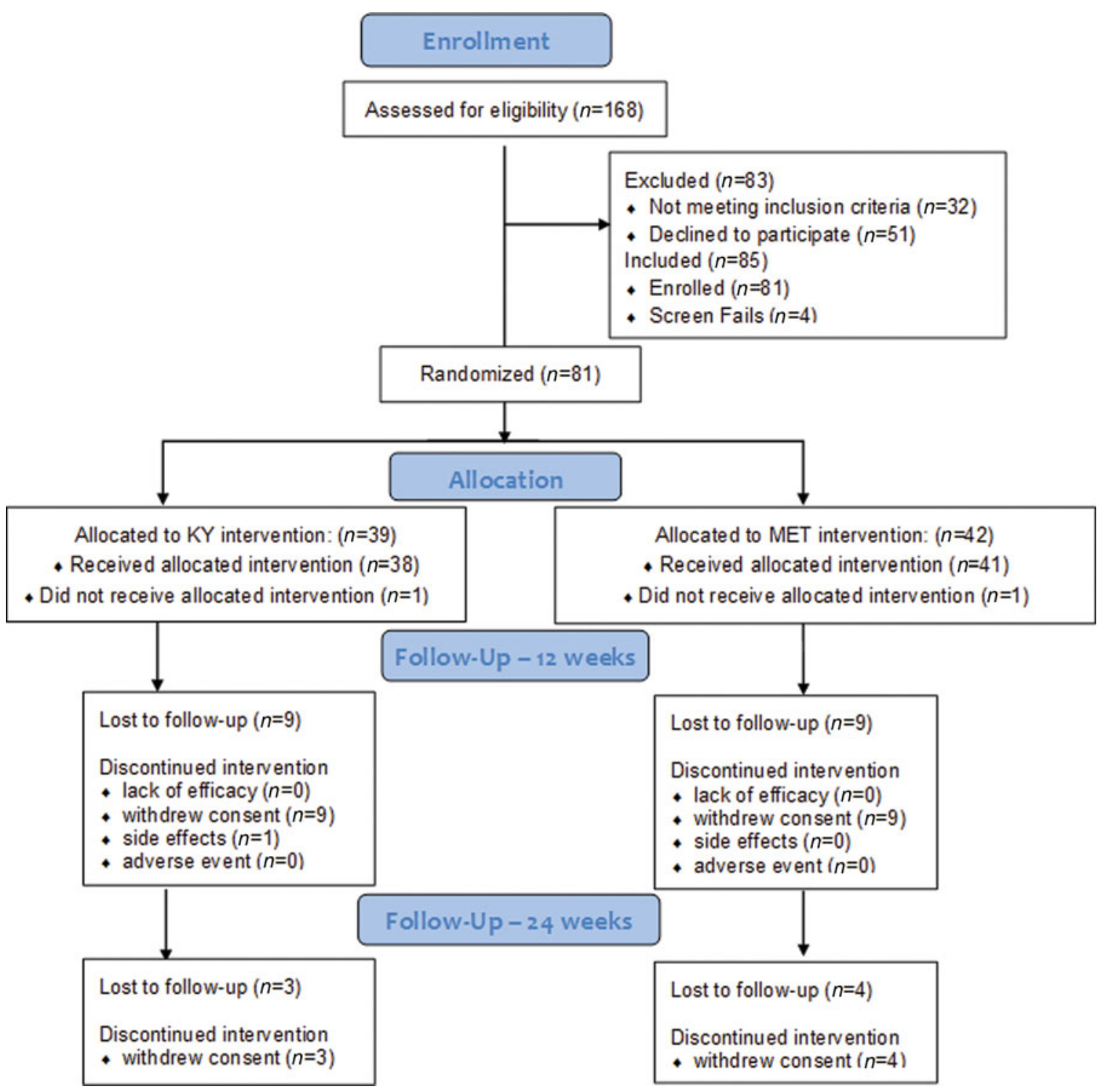

Figure 1. (Colour online) CONSORT flow diagram. 
Table 2. Cognitive measures in the Kundalini yoga and memory enhancement groups

\begin{tabular}{|c|c|c|c|c|c|}
\hline \multirow[b]{2}{*}{ MEASURES } & \multicolumn{3}{|c|}{ KY GROUP } & \multicolumn{2}{|c|}{ KY WITHIN-GROUP ANALYSIS } \\
\hline & $\begin{array}{l}\text { BASELINE } \\
\text { MEAN (SD) }\end{array}$ & $\begin{array}{l}12 \text {-WEEKS } \\
\text { MEAN (SD) }\end{array}$ & $\begin{array}{l}24 \text {-WEEKS } \\
\text { MEAN (SD) }\end{array}$ & $\begin{array}{l}\text { 12-WEEKS BASELINE } \\
\mathrm{t}, \mathrm{df}=74(\mathrm{p} \text {-VALUE), ES* }\end{array}$ & $\begin{array}{l}24 \text { WEEKS-BASELINE } \\
\mathrm{t}, \mathrm{df}=74(\mathrm{p} \text {-VALUE), ES }\end{array}$ \\
\hline \multicolumn{6}{|c|}{ MEMORY } \\
\hline HVLT total & $25.76(6.20)$ & $27.14(6.75)$ & $28.81(6.52)$ & $1.53(0.13), 0.28$ & $2.75(0.01), 0.54$ \\
\hline $\begin{array}{l}\text { HVLT } \\
\text { delayed }\end{array}$ & $9.03(2.70)$ & $9.48(1.86)$ & $9.73(2.22)$ & $1.30(0.20), 0.24$ & $1.54(0.13), 0.30$ \\
\hline $\begin{array}{l}\text { WMS Imm } \\
\text { recall }\end{array}$ & $17.19(9.53)$ & $22.28(8.15)$ & $23.35(7.81)$ & $5.21(<0.0001), 0.95$ & $5.00(<0.0001), 0.98$ \\
\hline $\begin{array}{l}\text { WMS delayed } \\
\text { recall }\end{array}$ & $5.22(2.88)$ & $6.72(1.85)$ & $7.58(4.30)$ & $5.24(<0.0001), 0.96$ & $3.32(0.001), 0.65$ \\
\hline Rey-O 3-min & $16.01(5.93)$ & $18.90(6.85)$ & $18.77(8.48)$ & $2.96(0.004), 0.54$ & $1.98(0.05), 0.39$ \\
\hline Rey-O 30-min & $16.71(6.36)$ & $19.10(7.65)$ & $20.31(7.11)$ & $2.64(0.01), 0.48$ & $3.81(0.0003), 0.75$ \\
\hline \multicolumn{6}{|c|}{ EXECUTIVE FUNCTION } \\
\hline Trails B (sec) & $112.26(60.09)$ & $96.28(41.25)$ & $89.45(40.39)$ & $-2.52(0.01),-0.46$ & $-3.80(0.0003),-0.75$ \\
\hline $\begin{array}{l}\text { Stroop } \\
\quad \text { Word-Color }\end{array}$ & $37.41(11.62)$ & $42.90(12.02)$ & $43.12(12.99)$ & $3.88(0.0002), 0.71$ & $3.06(0.003), 0.60$ \\
\hline Animals & $18.79(5.05)$ & $20.69(4.83)$ & $21.15(4.98)$ & $2.26(0.03), 0.41$ & $2.75(0.01), 0.54$ \\
\hline MEASURES & $\begin{array}{l}\text { BASELINE } \\
\text { MEAN (SD) }\end{array}$ & $\begin{array}{l}\text { MET GROUP } \\
\text { 12-WEEKS } \\
\text { MEAN (SD) }\end{array}$ & $\begin{array}{l}\text { 24-WEEKS } \\
\text { MEAN (SD) }\end{array}$ & \multicolumn{2}{|c|}{ MET WITHIN-GROUP ANALYSIS } \\
\hline \multicolumn{6}{|c|}{ MEMORY } \\
\hline HVLT total & $26.02(5.42)$ & $28.90(4.19)$ & $27.96(5.44)$ & $2.94(0.004), 0.54$ & $1.74(0.09), 0.35$ \\
\hline $\begin{array}{l}\text { HVLT } \\
\text { delayed }\end{array}$ & $8.93(2.26)$ & $9.93(2.08)$ & $9.60(2.74)$ & $2.54(0.01), 0.46$ & $1.82(0.07), 0.36$ \\
\hline $\begin{array}{l}\text { WMS Imm } \\
\text { recall }\end{array}$ & $18.27(7.90)$ & $24.00(6.49)$ & $24.72(5.62)$ & $5.82(<0.0001), 1.06$ & $5.59(<0.0001), 1.18$ \\
\hline $\begin{array}{l}\text { WMS delayed } \\
\text { recall }\end{array}$ & $6.27(2.39)$ & $7.27(1.17)$ & $7.36(1.47)$ & $3.22(0.002), 0.59$ & $1.68(0.10), 0.34$ \\
\hline Rey-O 3-min & $16.80(5.29)$ & $21.22(6.76)$ & $22.63(7.19)$ & $3.92(0.0002), 0.72$ & $4.12(0.0001), 0.82$ \\
\hline Rey-O 30-min & $16.69(5.34)$ & $20.88(7.38)$ & $23.60(6.92)$ & $3.53(0.001), 0.64$ & $6.50(<0.0001), 0.76$ \\
\hline \multicolumn{6}{|c|}{ EXECUTIVE FUNCTION } \\
\hline Trails B (sec) & $89.25(35.74)$ & $89.89(34.17)$ & $83.99(29.77)$ & $0.15(0.88), 0.03$ & $-1.35(0.18),-0.27$ \\
\hline $\begin{array}{l}\text { Stroop } \\
\quad \text { Word-Color }\end{array}$ & $43.22(13.02)$ & $44.30(11.67)$ & $42.92(14.46)$ & $0.73(0.46), 0.13$ & $0.00(1.0), 0.00$ \\
\hline Animals & $19.95(4.09)$ & $20.17(5.02)$ & $20.19(5.18)$ & $0.48(0.63), 0.09$ & $0.96(0.34), 0.19$ \\
\hline
\end{tabular}

HVLT Total $=$ Hopkins Verbal Learning Test Total Recall; HVLT Delayed = Hopkins Verbal Learning Test Delayed Recall; WMS Imm recall $=$ Wechsler Memory Scale-III Verbal Paired Associate test Immediate Recall; WMS Delayed recall = Wechsler Memory Scale-III Verbal Paired Associate test Delayed Recall; Rey-O = Rey-Osterrieth complex figure test; Trails B = Trail Making Test B; KY = Kundalini yoga.

${ }^{*} \mathrm{ES}=$ estimated effect size (Cohen's d).

several significant within-group changes for both KY and MET (see Table 2). At 12 weeks, both the $\mathrm{KY}$ and MET groups showed significant withingroup improvements in immediate and delayed recall verbal memory (WMS Logical Memory; ES $(\mathrm{KY})=0.95,0.96 ; \mathrm{ES}(\mathrm{MET})=1.06,0.59)$ and visual memory (Rey-O; ES $(\mathrm{KY})=0.54$, 0.48 ; ES $($ MET) $=0.64,0.72)$. Only the MET group showed significant improvement in verbal memory (HVLT; ES $($ MET) $=0.54,0.46)$. The change in HVLT scores over time is shown in Figure 2.

At 24 weeks, significant within-group improvements were noted for both the KY and MET groups in WMS Logical Memory immediate recall $(\mathrm{ES}(\mathrm{KY})=0.98 ; \mathrm{ES}(\mathrm{MET})=1.18)$ and on the Rey-O 3-minute (ES (KY) =0.39; ES $(\mathrm{MET})=0.82)$ and 30 -minute visual memory $(\mathrm{ES}(\mathrm{KY})=0.75$; ES $(\mathrm{MET})=0.76)$. However, only the KY group showed sustained significant 
Table 3. Mood measures in the KY and MET groups

\begin{tabular}{|c|c|c|c|c|c|}
\hline \multirow[b]{2}{*}{ MEASURES } & \multicolumn{3}{|c|}{ KY GROUP } & \multicolumn{2}{|c|}{ KY WITHIN-GROUP ANALYSIS } \\
\hline & $\begin{array}{l}\text { BASELINE } \\
\text { MEAN (SD) }\end{array}$ & $\begin{array}{l}12 \text {-WEEKS } \\
\text { MEAN (SD) }\end{array}$ & $\begin{array}{l}24 \text {-WEEKS } \\
\text { MEAN (SD) }\end{array}$ & $\begin{array}{l}\text { 12-WEEKS BASELINE } \\
\mathrm{t}, \mathrm{df}=74(\mathrm{p} \text {-VALUE }), \mathrm{ES}\end{array}$ & $\begin{array}{l}24 \text { WEEKS-BASELINE } \\
\mathrm{t}, \mathrm{df}=74(\mathrm{p} \text {-VALUE }), \mathrm{ES}\end{array}$ \\
\hline GDS & $7.70(6.57)$ & $4.48(4.66)$ & $5.23(5.47)$ & $-3.37(0.001),-0.62$ & $-2.73(0.01),-0.54$ \\
\hline AES & $43.89(7.98)$ & $48.41(6.80)$ & $46.69(6.72)$ & $2.84(0.01), 0.52$ & $1.76(0.08), 0.35$ \\
\hline \multirow[t]{3}{*}{ CDRISC } & $75.08(13.66)$ & $78.41(10.56)$ & $78.12(10.51)$ & $2.18(0.03), 0.40$ & $1.49(0.14), 0.29$ \\
\hline & MET GROUP & & & & \\
\hline & BASELINE & 12-WEEKS & 24-WEEKS & \multirow{2}{*}{\multicolumn{2}{|c|}{ MET WITHIN-GROUP ANALYSIS }} \\
\hline MEASURES & MEAN (SD) & MEAN (SD) & MEAN (SD) & & \\
\hline GDS & $6.51(5.28)$ & $4.53(3.51)$ & $4.60(4.18)$ & $-1.60(0.11),-0.30$ & $-0.91(0.36), 0.18$ \\
\hline AES & $42.17(6.54)$ & $49.93(8.98)$ & $49.50(11.11)$ & $4.90(<0.0001), 0.89$ & $4.34(<0.0001), 0.87$ \\
\hline CDRISC & $72.29(14.38)$ & $74.1(14.90)$ & $72.84(13.36)$ & $1.03(0.31), 0.19$ & 0.08 (0.93), 0.02 \\
\hline
\end{tabular}

GDS = geriatric depression scale; AES = apathy evaluation scale; CDRISC = Connor-Davidson resilience scale; KY = Kundalini yoga

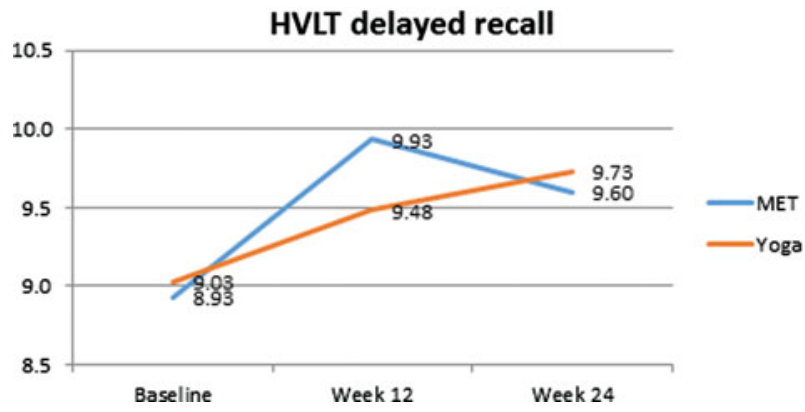

Figure 2. (Colour online) HVLT delayed recall scores in Kundalini yoga and memory enhancement training.

improvements on other measures, including WMS Logical Memory delayed recall $(\mathrm{ES}(\mathrm{KY})=0.65)$ and HVLT total $(\mathrm{ES}(\mathrm{KY})=0.54)$.

\section{Analysis of change in executive functioning over time}

The two intervention groups differed significantly $(\mathrm{F}(2,74)=3.24, \mathrm{p}=0.04)$ in their change in Trails $\mathrm{B}$ scores both at 12 weeks $(\mathrm{t}(74)=2.27, \mathrm{p}=0.03$; effect size, $\mathrm{ES}=-0.46)$ and at 24 weeks $(\mathrm{t}(74)$ $=2.16, \mathrm{p}=0.03$; $\mathrm{ES}=-0.75$ ) follow-up postintervention, favoring the KY group. While change in no other executive functioning scores reached significance for the between-group comparisons, there were several significant within group changes for KY, as shown in Table 2.

Only the KY group showed significant improvement in Stroop Word-Color Task (ES (KY) $=0.71)$, Trails $\mathrm{B}(\mathrm{ES} \quad(\mathrm{KY})=-0.46)$ and Animals $(\mathrm{ES}(\mathrm{KY})=0.41)$ ) at week 12. Further, only the KY group showed sustained significant improvements on Stroop Color-Word (ES (KY) $=$ $0.60)$, Trails $\mathrm{B}(\mathrm{ES}(\mathrm{KY})=-0.75)$ and Animal Naming $(\mathrm{ES}(\mathrm{KY})=0.54)$ at 24 weeks.

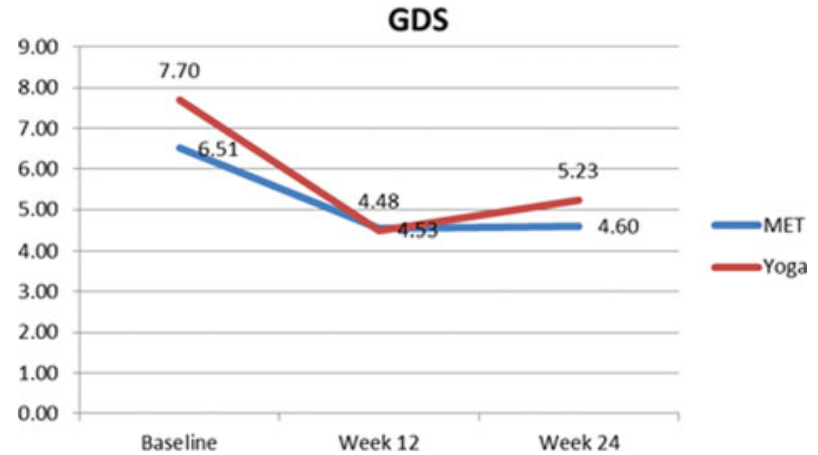

Figure 3. (Colour online) GDS scores in Kundalini yoga and memory enhancement training.

\section{Analysis of mood, apathy, and resilience over time}

Significant within-group improvements were obtained for both the KY and MET groups in apathy (AES: ES $(\mathrm{KY})=0.52$; ES $(\mathrm{MET})=0.89)$ at 12 weeks. Only the KY group showed significant improvements in depression ratings (GDS: ES $(\mathrm{KY})=-0.62)$ and resilience (CDRISC: ES $(\mathrm{KY})=0.40)$ at 12 weeks. At 24 -weeks postintervention, the MET group showed sustained significant improvement in apathy (ES (MET) $=0.87)$, and the $\mathrm{KY}$ group showed sustained significant improvement in depression $(\mathrm{ES}(\mathrm{KY})=$ -0.54). No between-group comparisons reached statistical significance. Changes in GDS and CDRISC scores over time are seen in Figures 3 and 4 and Table 3.

\section{Discussion}

This is the first RCT to explore the effects of $\mathrm{KY}$ in comparison to MET in an MCI cohort. 


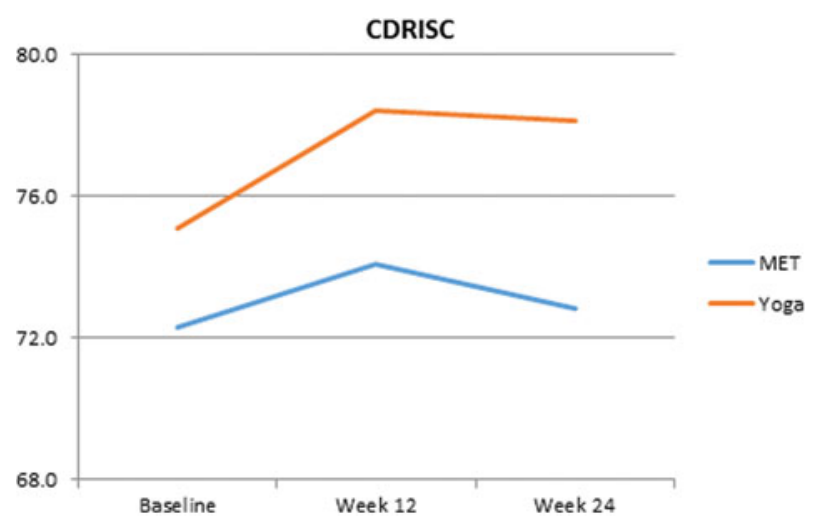

Figure 4. (Colour online) CD-RISC scores in Kundalini yoga and memory enhancement training.

In summary, the study found that KY had similar effects of memory, with additional beneficial effects on executive functioning and mood symptoms. These findings were consistent with our hypotheses.

There is a relative dearth of studies examining yoga and its effects on memory enhancement (Marciniak et al., 2014). We are not aware of previous studies exploring $\mathrm{KY}$ yoga in MCI patients. One main study of which we are aware explores the effects of yoga and exercise in 135 healthy men and women aged 65-85 years (Oken et al., 2006). In this study, participants were exposed to 6 months of Hatha yoga classes, walking classes, or wait-list control; participants were screened with a variety of mood and cognition tests (e.g. Stroop test). Interestingly, after the intervention, there were no effects from either of the active interventions on any of the cognitive and alertness outcome measures. The yoga intervention produced improvements in physical measures (e.g. timed 1-legged standing, forward flexibility), as well as a number of quality-of-life measures related to sense of well-being and energy and fatigue compared to controls. Interesting, a previous pilot study on KK meditation demonstrated activation of the brain areas associated with attention and exclusive functions (frontal area, cingulate cortex), which takes places during the meditation (Newberg et al., 2010).

We explain the "brain-fitness" effects of KY on multiple domains and on executive functions by the multi-component training using $\mathrm{KY}$ classes, and encapsulated KK meditation. We attribute the cognitive improvement in memory and executive function to the "brain fitness effect" of the daily "mind exercise" with the use of the alternating components of the chanting mantra meditation (KK) with mudras and visualization that may strengthen specific verbal and visual skills, and enhance global awareness and attention, as well as weekly $\mathrm{KY}$ classes that also represent multi-component exercise with additional stressreducing effect. This is consistent with the recent neural evidence showing that $\mathrm{KY}$ is associated with enhanced neural activity and structural changes in brain circuits associated with executive function (Marciniak et al., 2014). These findings are also consistent with our recently published report documenting increased connectivity in the language network on fMRI in association with performance on verbal memory resulting from $\mathrm{KY}+\mathrm{KK}$ intervention compared to MET control group (Eyre et al., 2016). Collectively, results from the present study and previous neuroimaging studies published by our group suggest that KY can increase "brain fitness" with increased connectivity and improved cognitive performance on the tests of memory and executive function, along with improvement in mood, apathy, and psychological resilience, and these effects may be sustained over time, beyond those offered by MET.

Yoga interventions have shown promise in addressing depressive symptoms in older adults. Prior review of published RCTs of yoga for depression in adults revealed that while all trials found benefit trial methodologies have generally been weak with lack of blinding, short duration of the intervention, variable outcome measures, limited information about participants, randomization procedures, compliance, and dropout rates (Pilkington et al., 2005). Comparative studies of yoga have likewise been limited, with one trial demonstrating that yoga may provide benefit as an augmentation strategy for antidepressant treatment (Janakiramaiah et al., 2000). Yoga is commonly used in combination with other treatments for depression, anxiety, and stress-related disorders. Data on use of yoga for anxiety and depression in older adults are more limited; however, one significant study of 69 older adults in India did compare the impact of yoga to Ayurveda or a wait-list control condition on sleep and depressive symptoms (Krishnamurthy and Telles, 2007). Participants in the yoga group practiced physical postures, relaxation techniques, regulated breathing, devotional songs, and attended lectures for more than $7 \mathrm{~h}$ a week during the course of the 6month trial. Practice of yoga significantly impacted quality of sleep and level of depressive symptoms when compared to the two control conditions, neither of which demonstrated significant effects. In particular, depressive symptoms, as measured by the short form of the GDS, decreased in the yoga group from a baseline average of 10.68.1 by 3 months and 6.7 by 6 months. The average time to fall asleep decreased in the yoga group by 10 minutes, while total number of hours 
slept increased by 60 minutes, and resulted in a greater feeling of being rested after 6 months. A recent study by Shahidi et al. (2011) compared the effectiveness of laughter yoga, group exercise therapy, and control in decreasing depression in older adult women (60-80 years). In this study, 70 depressed women were chosen if their GDS was $>10$. This study went for 10 sessions and found a significant improvement in depression score with both yoga and group exercise therapy as compared with control.

Overall, our pilot study provides novel and promising observations of cognitive benefits of yoga compared to the "gold standard" memory enhancement. However, because of its pilot nature, the study may not be powered to detect differences on multiple cognitive domains. Additionally, we do not have long-term follow-up, which means we are unable to explore cognitive decline toward dementia. A considerable number of eligible participants declined to participate, with the most cited reasons being logistic issues, such as the frequency of visits, and duration of the trial. However, a key point of our study was the high satisfaction with the intervention, which led to minimal dropout once the participants were enrolled. We are not able to separate the difference in the impact of multiple components of the KY and $\mathrm{KK}$ practice. Future research may attempt to separate the components of $\mathrm{KK}$ meditation to examine which specific activity (chanting, hand mudras, and visualization of light) promotes the enhancements reported in the present study as well as previous studies. Moreover, future studies may also separate the weekly class component and the at-home daily meditation practice to examine the effects of social interaction, class engagement, and yoga exercises. It is also possible that some of the maintenance effects were due to homework practice of KY and MET. Thus, future research may aim to investigate maintenance effects beyond 6 months and with more thorough investigation of program adherence.

\section{Conclusion}

This is the first RCT to compare KY effects on cognition and mood compared to gold standard, active control MET, for individuals with MCI. Both groups demonstrated improvement in verbal and visual memory. The KY group showed broader effect on executive functioning, depressed mood, and resilience with greater and sustained improvement in mood, compared to MET. These encouraging effects of yoga intervention should be further addressed in future longitudinal clinical trials directed at prevention of cognitive decline that will integrate the use of biomarkers of treatment response to shed light on the underlying mechanisms of response to the interventions.

\section{Conflict of interest}

None.

\section{Description of authors' roles}

HY, NSC, HL, LE, KVD were all involved in the collection of data. HE, HY, AL, PP, NSC, PS, KN, $\mathrm{BB}, \mathrm{DK}, \mathrm{BA}, \mathrm{LE}, \mathrm{KVD}$, and HL were all involved in the analysis of data, interpretation, drafting and completion of the manuscript. All authors approved the final manuscript.

\section{Acknowledgments}

Dr Lavretsky received grant support from the Forest Research Institute. Alzheimer's Research and Prevention Foundation provided funding for this study. Other sources of funding are as follows: NIH grants MH077650, MH086481, AT009198, and AT008383.

\section{References}

Abbott, R. and Lavretsky, H. (2013). Tai Chi and Qigong for the treatment and prevention of mental disorders. Psychiatric Clinics of North America, 36, 109-119.

American Heart Association (1990). Stroke Risk Factor Prediction Chart. Dallas, TX: American Heart Association.

Black, D. S. et al. (2013). Yogic meditation reverses NF-kappaB and IRF-related transcriptome dynamics in leukocytes of family dementia caregivers in a randomized controlled trial. Psychoneuroendocrinology, 38, 348-355.

Connor, K. M. and Davidson, J. R. (2003). Development of a new resilience scale: the Connor-Davidson Resilience Scale (CD-RISC). Depress Anxiety, 18, 76-82.

Endicott, J., Nee, J., Harrison, W. and Blumenthal, R. (1993). Quality of life enjoyment and satisfaction questionnaire: a new measure. Psychopharmacology Bulletin, 29, 321-326.

Eyre, H. A. et al. (2016). Changes in neural connectivity and memory following a yoga intervention for older adults: a pilot study. Fournal of Alzheimers Disease, 52(2), 673-684.

Fahn, S. and Elton, R. (1987). Unified Parkinson's disease rating scale. In S. Fahn, C. Marsden, M. Goldstein and D. Calne (Eds.). Recent Developments in Parkinson's Disease. Florham Park, NJ: Macmillan Healthcare Information.

First, M. B., Spitzer, R. L., Gibbon, M. and Williams, J. B. W. (2002). Structured Clinical Interview for DSM-IV-TR Axis I Disorders, Research Version, Patient 
Edition. (SCID-I/P) New York State Psychiatric Institute, NY: Biometrics Research.

Flak, M. M., Hernes, S. S., Skranes, J. and Lohaugen, G. C. (2014). The memory aid study: protocol for a randomized controlled clinical trial evaluating the effect of computer-based working memory training in elderly patients with mild cognitive impairment (MCI). Trials, 15, 156.

Folstein, M. F., Folstein, S. E. and McHugh, P. R. (1975). "Mini-mental state". A practical method for grading the cognitive state of patients for the clinician. Fournal of Psychiatric Research, 12, 189-198.

Fuld, P. A., Masur, D. M., Blau, A. D., Crystal, H. and Aronson, M. K. (1990). Object-memory evaluation for prospective detection of dementia in normal functioning elderly: predictive and normative data. Fournal of Clinical and Experimental Neuropsychology, 12, 520-528.

Golden, C. J. (1975). The measurement of creativity by the stroop color and word test. Fournal of Personality Assessment, 39, 502-506.

Gothe, N. P., Kramer, A. F. and McAuley, E. (2014). The effects of an 8-week Hatha yoga intervention on executive function in older adults. Fournal of Gerontology. Series $A$ Biological Sciences and Medical Sciences, 69, 1109-1116.

Gross, A. L. and Rebok, G. W. (2011). Memory training and strategy use in older adults: results from the ACTIVE study. Psychology and Aging, 26, 503-517.

Hughes, C. P., Berg, L., Danziger, W. L., Coben, L. A. and Martin, R. L. (1982). A new clinical scale for the staging of dementia. British fournal of Psychiatry, 140, 566-572.

Innes, K. E., Selfe, T. K., Khalsa, D. S. and Kandati, S. (2016a). Effects of meditation versus music listening on perceived stress, mood, sleep, and quality of life in adults with early memory loss: a pilot randomized controlled trial. fournal of Alzheimers Disease, 52, 1277-1298.

Innes, K. E., Selfe, T. K., Khalsa, D. S. and Kandati, S. (2016b). A randomized controlled trial of two simple mind-body programs, Kirtan Kriya meditation and music listening, for adults with subjective cognitive decline: feasibility and acceptability. Complementary Therapies in Medicine, 26, 98-107.

Janakiramaiah, N., Gangadhar, B. N., Naga Venkatesha Murthy, P. J., Harish, M. G., Subbakrishna, D. K. and Vedamurthachar, A. (2000). Antidepressant efficacy of Sudarshan Kriya Yoga (SKY) in melancholia: a randomized comparison with electroconvulsive therapy (ECT) and imipramine. Fournal of Affective Disorders, 57, 255-259.

Jean, L., Bergeron, M. E., Thivierge, S. and Simard, M. (2010). Cognitive intervention programs for individuals with mild cognitive impairment: systematic review of the literature. American fournal of Geriatric Psychiatry, 18, 281-296.

Khalsa, D. S. (2015). Stress, meditation, and Alzheimer's disease prevention: where the evidence stands. Fournal of Alzheimers Disease, 48, 1-12.

Krishnamurthy, M. N. and Telles, S. (2007). Assessing depression following two ancient Indian interventions: effects of yoga and ayurveda on older adults in a residential home. Fournal of Gerontological Nursing, 33, 17-23.
Lavretsky, H. (2009). Complementary and alternative medicine use for treatment and prevention of late-life mood and cognitive disorders. Aging Health, 5, 61-78.

Lavretsky, H. et al. (2013). A pilot study of yogic meditation for family dementia caregivers with depressive symptoms: effects on mental health, cognition, and telomerase activity. International Fournal of Geriatric Psychiatry, 28, 57-65.

Lingjaerde, O., Ahlfors, U. G., Bech, P., Dencker, S. J. and Elgen, K. (1987). The UKU side effect rating scale. A new comprehensive rating scale for psychotropic drugs and a cross-sectional study of side effects in neuroleptic-treated patients. Acta Psychiatrica Scandinavica Supplementum, 334, 1-100.

Reitan, R. M. (1958). Validity of the trail making test as an indicator of organic brain damage. Perceptual and Motor Skills, 8, 271-276.

Marciniak, R., Sheardova, K., Cermakova, P., Hudecek, D., Sumec, R. and Hort, J. (2014). Effect of meditation on cognitive functions in context of aging and neurodegenerative diseases. Frontiers in Behavioral Neuroscience, 8, 17.

Marin, R. S., Biedrzycki, R. C. and Firinciogullari, S. (1991). Reliability and validity of the apathy evaluation scale. Psychiatry Research, 38, 143-162.

McCarty, D. L. (1980). Investigation of a visual imagery mnemonic device for acquiring face-name associations. fournal of Experimental Psychology Human Learning, 6, 145-155.

Miller, M. D. et al. (1992). Rating chronic medical illness burden in geropsychiatric practice and research: application of the Cumulative Illness Rating Scale. Psychiatry Research, 41, 237-248.

Newberg, A. B., Wintering, N., Khalsa, D. S., Roggenkamp, H. and Waldman, M. R. (2010). Meditation effects on cognitive function and cerebral blood flow in subjects with memory loss: a preliminary study. Fournal of Alzheimers Disease, 20, 517-526.

Oken, B. S. et al. (2006). Randomized, controlled, six-month trial of yoga in healthy seniors: effects on cognition and quality of life. Alternative Therapies in Health and Medicine, 12, 40-47.

Petersen, R. C. (2004). Mild cognitive impairment as a diagnostic entity. Fournal of Internal Medicine, 256, 183-194.

Pilkington, K., Kirkwood, G., Rampes, H. and Richardson, J. (2005). Yoga for depression: the research evidence. Fournal of Affective Disorders, 89, 13-24.

Sager, M. A., Hermann, B. P., La Rue, A. and Woodard, J. L. (2006). Screening for dementia in community-based memory clinics. WMF, 105, 25-29.

Shahidi, M. et al. (2011). Laughter yoga versus group exercise program in elderly depressed women: a randomized controlled trial. International fournal of Geriatric Psychiatry, 26, 322-327.

Shapiro, A. M., Benedict, R. H., Schretlen, D. and Brandt, J. (1999). Construct and concurrent validity of the Hopkins Verbal Learning Test-revised. Clinical Neuropsychology, 13, 348-358.

Shin, M. S., Park, S. Y., Park, S. R., Seol, S. H. and Kwon, J. S. (2006). Clinical and empirical applications of 
the Rey-Osterrieth complex figure test. Nature Protocol, 1, 892-899.

Simon, S. S., Yokomizo, J. E. and Bottino, C. M. (2012). Cognitive intervention in amnestic Mild Cognitive Impairment: a systematic review. Neuroscience $\mathcal{E}$ Biobehavioral Reviews, 36, 1163-1178.

Truelsen, T., Lindenstrom, E. and Boysen, G. (1994). Comparison of probability of stroke between the Copenhagen city heart study and the framingham study. Stroke, 25, 802-807.

United Nations, Department of Economic and Social Affairs, Population Division (2013). World Population Ageing 2013. New York, NY: United Nations. ST/ESA/SER.A/348.
Verhaeghen, P., Marcoen, A. and Goossens, L. (1992). Improving memory performance in the aged through mnemonic training: a meta-analytic study. Psychology and Aging, 7, 242-251.

Ware, J. E. J., Kosinski, M. and Keller, S. D. (1994). SF-36 Physical and Mental Health Summary Scores: A User's Manual. Boston, MA: The Health Institute, New England Medical Center.

Wilkinson, G. S. and Robertson, G. J. (2006). Wide Range Achievement Test 4 Professional Manual. Lutz, FL: Psychological Assessment Resources.

Yesavage, J. A. et al. (1982). Development and validation of a geriatric depression screening scale: a preliminary report. Fournal of Psychiatric Research, 17, 37-49. 